\title{
Mammographic density as an image-based biomarker of therapy response in neoadjuvant-treated breast cancer patients
}

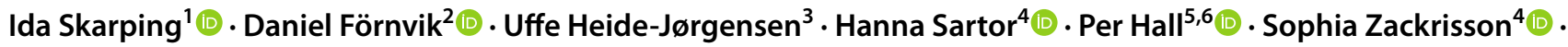 \\ Signe Borgquist ${ }^{1,7}$ (D)
}

Received: 24 July 2020 / Accepted: 4 December 2020 / Published online: 30 December 2020

(c) The Author(s) 2020

\begin{abstract}
Purpose Personalized cancer treatment requires predictive biomarkers, including image-based biomarkers. Breast cancer (BC) patients receiving neoadjuvant chemotherapy (NACT) are in a clinically vulnerable situation with the tumor present. This study investigated whether mammographic density (MD), assessed pre-NACT, is predictive of pathological complete response (pCR).

Methods A total of 495 BC patients receiving NACT in Sweden 2005-2019 were included, merged from two different cohorts. Cohort 1 was retrospectively collected $(n=295)$ and cohort 2 was prospectively collected $(n=200)$. Mammograms were scored for MD pre-NACT according to the Breast Imaging-Reporting and Data System (BI-RADS), 5th Edition. The association between MD and accomplishing pCR post-NACT was analyzed using logistic regression models-for the whole cohort, stratified by menopausal status, and in different St. Gallen surrogate subtypes.

Results In comparison to patients with low MD (BI-RADS a), the multivariable-adjusted odds ratio (OR) of accomplishing pCR following NACT was on a descending scale: 0.62 (95\% confidence interval (CI) 0.24-1.57), 0.38 (95\% CI 0.14-1.02), and 0.32 (95\% CI 0.09-1.08) for BI-RADS b, c, and d, respectively. For premenopausal patients selectively, the corresponding point estimates were lower, although wider CIs: 0.31 (95\% CI 0.06-1.62), 0.24 (95\% CI 0.04-1.27), and 0.13 (95\% CI 0.02-0.88). Subgroup analyses based on BC subtypes resulted in imprecise estimates, i.e., wide CIs.

Conclusions It seemed as though patients with higher MD at baseline were less likely to reach pCR after NACT-a finding more pronounced in premenopausal women. Larger multicenter studies are needed to enable analyses and interpretation for different BC subtypes.
\end{abstract}

Keywords Breast cancer $\cdot$ Mammography $\cdot$ Breast density $\cdot$ Neoadjuvant chemotherapy

\begin{tabular}{|c|c|}
\hline Abb & ons \\
\hline $\mathrm{BC}$ & Breast cancer \\
\hline MD & Mammographic density \\
\hline
\end{tabular}

Supplementary Information The online version of this article (https://doi.org/10.1007/s10552-020-01379-w) contains supplementary material, which is available to authorized users.

Ida Skarping

ida.skarping@med.lu.se

1 Division of Oncology and Pathology, Department of Clinical Sciences, Lund University, Skane University Hospital, Barngatan 4, 22185 Lund, Sweden

2 Department of Translational Medicine, Medical Radiation Physics, Lund University, Skane University Hospital, Malmö, Sweden

3 Department of Clinical Epidemiology, Aarhus University Hospital, Aarhus, Denmark

$\begin{array}{ll}\text { ER } & \text { Estrogen receptor } \\ \text { PR } & \text { Progesterone receptor } \\ \text { HER2 } & \text { Human epidermal growth factor receptor 2 } \\ \text { IHC } & \text { Immunohistochemistry } \\ \text { NACT } & \text { Neoadjuvant chemotherapy } \\ \text { pCR } & \text { Pathological complete response }\end{array}$

4 Department of Translational Medicine, Diagnostic Radiology, Lund University, Skane University Hospital, Lund and Malmö, Sweden

5 Department of Medical Epidemiology and Biostatistics, Karolinska Institute, Solna, Sweden

6 Department of Oncology, Södersjukhuset, Stockholm, Sweden

7 Department of Oncology, Aarhus University Hospital, Aarhus, Denmark 


$\begin{array}{ll}\text { BI-RADS } & \begin{array}{l}\text { Breast imaging reporting and data system } \\ \text { FEC }\end{array} \\ & \begin{array}{l}\text { Fluorouracil, epirubicin and } \\ \text { cyclophosphamide }\end{array} \\ \text { EC } & \text { Epirubicin and cyclophosphamide } \\ \text { IQR } & \text { Interquartile range } \\ \text { OR } & \text { Odds ratio } \\ \text { BMI } & \text { Body mass index } \\ \text { CI } & \text { Confidence interval }\end{array}$

\section{Introduction}

Breast cancer (BC) is the most common cancer in women, with more than two million new cases each year; it accounts for almost one in four cancer cases in women worldwide [1]. As many as $12 \%$ of the female population is affected by $\mathrm{BC}$ at some point during their lifetimes [2]. Mammographic density (MD) refers to the radiologically dense epithelium and stroma identified in a mammogram [3]. MD is one of the strongest risk factors for $\mathrm{BC}$, after aging and genetic mutations [2]. Although it is impossible to establish the cause of BC in specific cases, it is estimated that almost $30 \%$ of premenopausal and $15 \%$ of postmenopausal BC can be attributed to high MD alone [4].

Due to the cost and complexity of gene expression [5], as is mandatory for the intrinsic system developed by Perou and Sorlie [6], a surrogate classification system was developed based on the expression of a selected set of markers [7]: estrogen receptor (ER), progesterone receptor (PR), human epidermal growth factor receptor 2 (HER2), and the proliferation marker Ki67, as included in the 2011 St. Gallen International Consensus [8], all in an attempt to provide personalized cancer treatment. Currently, treatment decisions, preferably undertaken by a multidisciplinary team, are most often based on the immunohistochemistry (IHC)-based St. Gallen surrogate subtypes, histological grade, TNM stage (partly derived from radiology), and patient characteristics and preferences $[9,10]$.

The indication for neoadjuvant chemotherapy (NACT) in $\mathrm{BC}$ has broadened [9]. Hence, a larger proportion of patients receive their systemic treatment before surgery instead of after surgery, with equal long-term survival [11]. The proportion of $\mathrm{BC}$ patients accomplishing complete pathological response (pCR) following NACT, considered advantageous prognostically and used as a surrogate marker for long-term survival [12], varies depending on BC surrogate subtype [12]. High rates of pCR are most often achieved for the triple negative and HER2 positive subtypes [12]. However, because the majority of patients do not accomplish pCR [12], additional treatment predictive biomarkers, e.g., imaging biomarkers, are needed to offer future BC patients more individualized treatment and select the patients most likely to respond to NACT.

Previous studies [13-15], including two studies performed by our group [15, 16], have shown inconsistent results regarding MD as a predictive biomarker of response to NACT. One study shows no association between MD and pCR [14], whereas two other studies find an association between low MD and increased likelihood of pCR [13, 15]. In this study, based on two merged cohorts and, thus, adding up to the highest number of patients of the just-referenced studies, we investigated the role of MD at diagnosis, assessed via the clinically widespread Breast ImagingReporting and Data System (BI-RADS), 5th Edition [17], as a potential treatment predictive biomarker for $\mathrm{pCR}$ in a larger dataset and across different St. Gallen surrogate subtypes of $\mathrm{BC}$.

Fig. 1 Patient flow chart

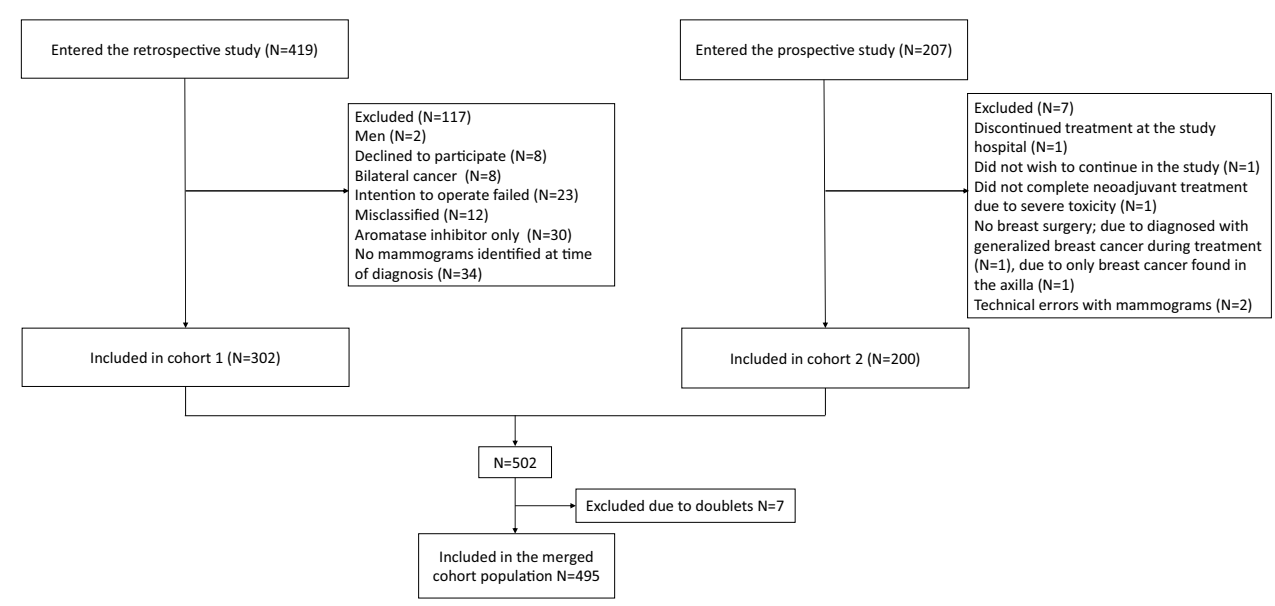




\section{Methods}

\section{Cohort}

A total of $495 \mathrm{BC}$ patients receiving NACT for BC were included in this study (Fig. 1). We combined two neoadjuvant cohorts: cohort 1, a retrospective cohort ("NeoMon") of 302 patients receiving NACT for BC during 2005-2016 [15], and cohort 2, a prospective cohort ("NeoDense") of 200 patients receiving NACT for BC during 2014-2019 [16] both at Skane University Hospital, Sweden. Seven patients were part of both cohorts and, hence, were excluded from cohort 1 before statistical analyses were performed. The details of the cohorts are previously described $[15,16]$. Here, the two cohorts are briefly recapitulated and described, respectively. Only female patients treated with NACT and undergoing the intended breast surgery were included in the study. Patients' characteristics were retrieved from medical charts for the retrospective cohort and from a study-specific patient questionnaire (filled in at the time of diagnosis) for the prospective cohort. Menopausal status at baseline was differently defined in the two cohorts, cohort 1: menopausal status was collected from patient records (perimenopausal patients were included in the postmenopausal group and when menopausal status was unknown, the patient was considered postmenopausal if $>55$ years), cohort 2: defined according to self-reported menstrual history (patients $>1$ year since the last period (not caused by birth control or recent pregnancy/breastfeeding) were considered postmenopausal); for the analyses of this study, patients $\geq 55$ years were considered postmenopausal and otherwise premenopausal. Patients received their oncological treatment according to the same guidelines.

For both cohorts, the standard NACT contained three series of fluorouracil, epirubicin, and cyclophosphamide (FEC) or epirubicin and cyclophosphamide (EC) followed by three series of taxanes (docetaxel or paclitaxel) and, in the case of HER2 positive tumor, combined with HER2blockade (trastuzumab/pertuzumab). In total, $87 \%$ of the patients received a chemotherapy regimen consisting of a combination of EC/FEC and docetaxel/paclitaxel. Additionally, a total of $10 \%$ of the patients received taxane-only NACT-regimen and a total of $2 \%$ of the patients received FEC/EC only. For the patients with HER2 positive tumors, the standard treatment differed between the two cohorts given the different time periods; in the retrospective cohort, a total of $97 \%(n=90)$ received single (trastuzumab) antiHER2 treatment, while the remainder $(n=3)$ received no anti-HER2 treatment. In the prospective cohort, a total of 94\% $(n=45)$ of the patients with HER2 positive tumors received double (trastuzumab and pertuzumab) blockade, while the remainder $(n=3)$ received single (trastuzumab)
HER2-blockade. Thus, overall, only $2 \%$ of patients with a HER2 positive tumor did not receive any anti-HER2 treatment at all.

Information about tumor pathology from the core biopsy at diagnosis and the surgical specimen following NACT was derived from clinical pathological reports. Following local and national guidelines defined identically for the two cohorts, tumor hormone receptor positivity was defined according to staining positive in $>10 \%$ of the tumor cells with IHC and HER2 status was defined as either 3+ with IHC and/or amplified with fluorescence in situ hybridization. The proliferation marker Ki67 was reported as a number from $0-100 \%$, depending on the percentage of the tumor cells that stained positive. Ki67 > $20 \%$ was considered highly proliferative and Ki67 $\leq 20 \%$ was considered low proliferative. The same definition for pCR was used in both cohorts, i.e., the absence of any residual invasive cancer in the resected breast after surgery as well as all sampled regional lymph nodes following completion of NACT [18].

Patients were assigned to one of the following St. Gallen surrogate subtypes: luminal A-like (ER+, PR+/-, HER2-, Ki67 $\leq 20 \%$ "low"); luminal B-like (ER+, PR+/-, HER2-, Ki67 > 20\% "high"); HER2 positive (ER+/-, PR+/-, HER2+, any Ki67), or triple negative (ER-, PR-, HER2-, any Ki67).

\section{Mammograms}

For cohort 1, we had access to digital vendor-processed mammograms at the time of diagnosis, while both digital unprocessed raw images and processed images were continuously assembled for cohort 2 .

For cohort 1, the mammographic examination was performed at three different sites within Skane, Sweden on the following machines: Fujifilm, GE Healthcare, Philips Healthcare, and Siemens Healthineers. Using images in all available views and both breasts, categorization according to BI-RADS breast composition 5th Edition [17] was retrospectively done by an experienced specialist in radiology (HS) blinded to all patient and tumor characteristics. If the breasts were not of equal MD, the denser breast was used to categorize MD as is recommended by the BI-RADS guidelines [17]. In case of inflammatory $\mathrm{BC}(n=10)$ the contralateral breast was used to categorize MD.

For cohort 2, mammograms were acquired on the following machines: GE, Philips, and Siemens. Categorization according to BI-RADS breast composition 5th Edition was done based on images in all available views from the contralateral breast at each radiological examination by the assigned breast radiologist in the clinic. The ipsilateral cancer-affected breast and the contralateral healthy breast 
showed good concordance in MD [16] in line with another study [19].

Information about tumor size (largest measurable diameter) was retrieved from clinical radiology reports (cohort 1) and study-specific forms (cohort 2). When both mammographic and ultrasound size estimation were available, the mean was used in the statistical analyses.

\section{Statistical analyses}

We summarized baseline patient characteristics for the combined cohorts by both BI-RADS level and pCR. Categorical variables were summarized by counts and percentages, and continuous variables by median and interquartile range (IQR). We present estimates and IQR and have purposely left out $p$-values to avoid misinterpretation and over-belief in such significance testing [20]. Next, we estimated the association between BI-RADS and pCR as expressed by odds ratios (ORs) using logistic regression. Crude, uni-, and multivariable-adjusted models were used, including only the complete cases $(n=491)$. Adjustments were made for age, and age, menopausal, and body mass index (BMI), respectively. We modeled the association both overall and in subgroups defined by menopausal and St. Gallen surrogate subtype status. We categorized BI-RADS in two ways: as a vs. b, c, and d, and as a/b vs c/d. In the regression models, we used generalized estimating equations to account for within-hospital correlations. All analyses were carried out using SAS (SAS Institute Inc., Version 9.4 Car, NC, USA).

\section{Results}

The patient and tumor characteristics of the 495 patients included in this study are presented according to BI-RADS category in Table 1. Most of the patients had intermediate dense breasts. A total of $84 \%$ of the patients were categorized as either BI-RADS b or c; only $5 \%$ and $11 \%$ were categorized as BI-RADS a and d, respectively. With increasing density according to BI-RADS, the median age and BMI declined expectedly and the proportion of premenopausal patients increased, whereas there was no association between tumor size and MD. Tumors in dense breasts (BIRADS $\mathrm{c}$ and d) were, to a higher degree, ER and PR positive compared to tumors in less dense breasts. HER2 status was fairly equally distributed according to BI-RADS category. A total of $77 \%$ of the tumors were highly proliferative (Ki67 $>20 \%$ ) and the proportions were similar in the different BIRADS categories. The median tumor size was $30 \mathrm{~mm}$ (IQR 22-40) (cohort 1: 32.5mm (IQR 23.3-45.0) and cohort 2: 29 $\mathrm{mm}$ (IQR 20.0-37.5)). Positive axillary lymph node status was verified pre-NACT for $67 \%$ of the patients.
A total of 102 patients (21\%) accomplished pCR (Table 2) (19\% in the retrospective cohort and 23\% in the prospective cohort). A total of $32 \%, 24 \%, 17 \%$, and $15 \%$ of the BI-RADS a, b, c, and d patients, respectively, reached pCR. Age, menopausal status, BMI, tumor size, number of births, and use of hormone replacement treatment was fairly equally distributed between patients who accomplished $\mathrm{pCR}$ and those who did not. Patients accomplishing pCR more often had ER and/or PR negative tumors, HER2 positive tumors, and highly proliferative tumors. The highest proportion of pCR was seen in the HER2 positive subtype (54\%), followed by the triple negative subtype (34\%). None of the 47 patients with luminal A-like tumors accomplished pCR.

A total of 491 patients had complete study data and were included in the logistic regression models (Fig. 2) addressing the association between MD assessed with BI-RADS and pCR following NACT in three different models. Overall, there was an inclination for the following: the higher the breast density, the lower the OR of accomplishing pCR; in comparison to patients with BI-RADS a, the ORs of accomplishing $\mathrm{pCR}$ in the multivariable-adjusted model were: BIRADS b 0.62 (95\% confidence interval (CI) 0.24-1.57), BI-RADS c 0.38 (95\% CI 0.14-1.02), and BI-RADS d 0.32 (95\% CI 0.09-1.08). For premenopausal patients, the corresponding ORs of accomplishing pCR in comparison to patients with BI-RADS a were: BI-RADS b 0.31 (95\% CI 0.06-1.62), BI-RADS c 0.24 (95\% CI 0.04-1.27), and BIRADS d 0.13 (95\% CI 0.02-0.88). Thus, in this model, the association was more pronounced when the premenopausal patients were analyzed separately, showing lower point estimates, although wider CI. When the cohort was dichotomized according to BI-RADS classification (a/b vs. c/d), patients with high MD had lower OR of accomplishing pCR (0.58 (95\% CI 0.36-0.92) in comparison to patients with low MD (Supplementary Material 1).

During analysis of subgroups according to St. Gallen surrogate subtypes, due to no and only a few events of $\mathrm{pCR}$ in the luminal A-like and luminal B-like groups, no logistic regression was performed for these subgroups. No significant association between MD and the likelihood of accomplishing pCR following NACT was found for the HER2 positive and triple negative subtypes, separately (Fig. 2). However, these subgroup analyses did not contradict the main results; the point estimates for both HER2 positive and triple negative subtypes indicated a lower likelihood of accomplishing pCR with high MD (BI-RADS $\mathrm{c}$ and d) in comparison to BI-RADS a. 
Table 1 Patients and tumor characteristics according to mammographic density at baseline

\begin{tabular}{|c|c|c|c|c|c|}
\hline & Total cohort & BI-RADS a & BI-RADS b & BI-RADS c & BI-RADS d \\
\hline Overall & 495 & 25 & 192 & 226 & 52 \\
\hline Age, median (IQR) & 53 (45 to 63$)$ & $59(56$ to 68$)$ & 58 (48 to 66$)$ & $50(42$ to 60$)$ & 46 (40 to 57$)$ \\
\hline BMI, median (IQR) & 25 (23 to 29$)$ & $31(28$ to 36$)$ & 26 (24 to 29$)$ & 24 (22 to 27$)$ & 23 (21 to 26$)$ \\
\hline Tumor size (mm), median (IQR) & $30(22$ to 40$)$ & 33 (24 to 39$)$ & $29(20$ to 38$)$ & $33(24$ to 43$)$ & $33(21$ to 40$)$ \\
\hline \multicolumn{6}{|l|}{ Menopausal status } \\
\hline Premenopausal & $269(54.3 \%)$ & $6(24.0 \%)$ & $78(40.6 \%)$ & $149(65.9 \%)$ & $36(69.2 \%)$ \\
\hline Postmenopausal & $226(45.7 \%)$ & $19(76.0 \%)$ & $114(59.4 \%)$ & $77(34.1 \%)$ & $16(30.8 \%)$ \\
\hline \multicolumn{6}{|l|}{ Any births } \\
\hline No children & $69(13.9 \%)$ & $2(8.0 \%)$ & $18(9.4 \%)$ & $40(17.7 \%)$ & $9(17.3 \%)$ \\
\hline 1 or more children & $425(85.9 \%)$ & $23(92.0 \%)$ & $173(90.1 \%)$ & $186(82.3 \%)$ & $43(82.7 \%)$ \\
\hline Missing & $1(0.2 \%)$ & $0(0.0 \%)$ & $1(0.5 \%)$ & $0(0.0 \%)$ & $0(0.0 \%)$ \\
\hline \multicolumn{6}{|l|}{ Ever hormone replacement therapy } \\
\hline Yes & $64(12.9 \%)$ & $4(16.0 \%)$ & $31(16.1 \%)$ & $25(11.1 \%)$ & $4(7.7 \%)$ \\
\hline No & $427(86.3 \%)$ & $21(84.0 \%)$ & $157(81.8 \%)$ & $201(88.9 \%)$ & $48(92.3 \%)$ \\
\hline Missing & $4(0.8 \%)$ & $0(0.0 \%)$ & $4(2.1 \%)$ & $0(0.0 \%)$ & $0(0.0 \%)$ \\
\hline \multicolumn{6}{|l|}{ ER } \\
\hline Positive (> 10\%) & $299(60.4 \%)$ & $10(40.0 \%)$ & $113(58.9 \%)$ & $138(61.1 \%)$ & $38(73.1 \%)$ \\
\hline Negative $(\leq 10 \%)$ & $187(37.8 \%)$ & $15(60.0 \%)$ & $75(39.1 \%)$ & $83(36.7 \%)$ & $14(26.9 \%)$ \\
\hline Missing & $9(1.8 \%)$ & $0(0.0 \%)$ & $4(2.1 \%)$ & $5(2.2 \%)$ & $0(0.0 \%)$ \\
\hline \multicolumn{6}{|l|}{ PR } \\
\hline Positive (> 10\%) & $238(48.1 \%)$ & $10(40.0 \%)$ & $81(42.2 \%)$ & $117(51.8 \%)$ & $30(57.7 \%)$ \\
\hline Negative $(\leq 10 \%)$ & $247(49.9 \%)$ & $15(60.0 \%)$ & $107(55.7 \%)$ & $103(45.6 \%)$ & $22(42.3 \%)$ \\
\hline Missing & $10(2.0 \%)$ & $0(0.0 \%)$ & $4(2.1 \%)$ & $6(2.7 \%)$ & $0(0.0 \%)$ \\
\hline \multicolumn{6}{|l|}{ HER2 } \\
\hline Positive & $141(28.5 \%)$ & $7(28.0 \%)$ & $64(33.3 \%)$ & $56(24.8 \%)$ & $14(26.9 \%)$ \\
\hline Negative & $338(68.3 \%)$ & $16(64.0 \%)$ & $121(63.0 \%)$ & $163(72.1 \%)$ & $38(73.1 \%)$ \\
\hline Missing & $16(3.2 \%)$ & $2(8.0 \%)$ & $7(3.6 \%)$ & $7(3.1 \%)$ & $0(0.0 \%)$ \\
\hline \multicolumn{6}{|l|}{ Ki67 } \\
\hline High $(>20 \%)$ & $381(77.0 \%)$ & $21(84.0 \%)$ & $152(79.2 \%)$ & $167(73.9 \%)$ & $41(78.8 \%)$ \\
\hline Low $(\leq 20 \%)$ & $54(10.9 \%)$ & $2(8.0 \%)$ & $17(8.9 \%)$ & $32(14.2 \%)$ & $3(5.8 \%)$ \\
\hline Missing & $60(12.1 \%)$ & $2(8.0 \%)$ & $23(12.0 \%)$ & $27(11.9 \%)$ & $8(15.4 \%)$ \\
\hline \multicolumn{6}{|l|}{ St. Gallen } \\
\hline Luminal A like & $47(9.5 \%)$ & $1(4.0 \%)$ & $16(8.3 \%)$ & $28(12.4 \%)$ & $2(3.8 \%)$ \\
\hline Luminal B like & $148(29.9 \%)$ & $5(20.0 \%)$ & $56(29.2 \%)$ & $66(29.2 \%)$ & $21(40.4 \%)$ \\
\hline HER2 positive & $141(28.5 \%)$ & $7(28.0 \%)$ & $64(33.3 \%)$ & $56(24.8 \%)$ & $14(26.9 \%)$ \\
\hline Triple negative & $121(24.4 \%)$ & $9(36.0 \%)$ & $42(21.9 \%)$ & $62(27.4 \%)$ & $8(15.4 \%)$ \\
\hline Missing & $38(7.7 \%)$ & $3(12.0 \%)$ & $14(7.3 \%)$ & $14(6.2 \%)$ & $7(13.5 \%)$ \\
\hline \multicolumn{6}{|l|}{ Lymph node status } \\
\hline Negative & $79(16.0 \%)$ & $3(12.0 \%)$ & $30(15.6 \%)$ & $39(17.3 \%)$ & $7(13.5 \%)$ \\
\hline Positive & $334(67.5 \%)$ & $17(68.0 \%)$ & $131(68.2 \%)$ & $148(65.5 \%)$ & $38(73.1 \%)$ \\
\hline Missing & $82(16.6 \%)$ & $5(20.0 \%)$ & $31(16.1 \%)$ & $39(17.3 \%)$ & $7(13.5 \%)$ \\
\hline
\end{tabular}

\section{Discussion}

In this study of $495 \mathrm{BC}$ patients from both a retrospective cohort and a prospective cohort, we found the following tendency: the higher the MD, the lower the likelihood of accomplishing pCR following NACT, most notably for premenopausal patients. The clinical interpretation is that MD, as assessed with BI-RADS, may be used as a predictive biomarker for NACT. Subgroup analysis based on St. Gallen surrogate subtypes resulted in imprecise estimates, though in line with the main results.

In our study, tumors in denser breasts (BI-RADS c and d) were more often ER and PR positive compared to tumors in less dense breasts; thus, luminal-like BC was 
Table 2 Patient and tumor characteristics at baseline according to pathological complete response

\begin{tabular}{|c|c|c|}
\hline & $\mathrm{pCR}$ & non $\mathrm{pCR}$ \\
\hline Overall & 102 & 393 \\
\hline \multicolumn{3}{|l|}{ BI-RADS } \\
\hline BI-RADS a & $8(7.8 \%)$ & $17(4.3 \%)$ \\
\hline BI-RADS b & $47(46.1 \%)$ & $145(36.9 \%)$ \\
\hline BI-RADS c & $39(38.2 \%)$ & $187(47.6 \%)$ \\
\hline BI-RADS d & $8(7.8 \%)$ & $44(11.2 \%)$ \\
\hline Age, median (IQR) & $54(46$ to 63$)$ & 53 (45 to 63$)$ \\
\hline BMI, median (IQR) & $25(23$ to 29$)$ & 25 (23 to 29$)$ \\
\hline Tumor size (mm), median (IQR) & $26(20$ to 35$)$ & $33(23$ to 40$)$ \\
\hline \multicolumn{3}{|l|}{ Menopausal status } \\
\hline Premenopausal & $53(52.0 \%)$ & $216(55.0 \%)$ \\
\hline Postmenopausal & $49(48.0 \%)$ & $177(45.0 \%)$ \\
\hline \multicolumn{3}{|l|}{ Any births } \\
\hline No children & $10(9.8 \%)$ & $59(15.0 \%)$ \\
\hline 1 or more children & $92(90.2 \%)$ & $333(84.7 \%)$ \\
\hline Missing & $0(0 \%)$ & $1(0.3 \%)$ \\
\hline \multicolumn{3}{|l|}{ Ever hormone replacement therapy } \\
\hline Yes & $16(15.7 \%)$ & $48(12.2 \%)$ \\
\hline No & $86(84.3 \%)$ & $341(86.8 \%)$ \\
\hline Missing & $0(0 \%)$ & $4(1.0 \%)$ \\
\hline \multicolumn{3}{|l|}{ ER } \\
\hline Positive (> 10\%) & $28(27.5 \%)$ & $271(69.0 \%)$ \\
\hline Negative $(\leq 10 \%)$ & $73(71.6 \%)$ & $114(29.0 \%)$ \\
\hline Missing & $1(1.0 \%)$ & $8(2.0 \%)$ \\
\hline \multicolumn{3}{|l|}{ PR } \\
\hline Positive (> 10\%) & $17(16.7 \%)$ & $221(56.2 \%)$ \\
\hline Negative $(\leq 10 \%)$ & $84(82.4 \%)$ & $163(41.5 \%)$ \\
\hline Missing & $1(1.0 \%)$ & $9(2.3 \%)$ \\
\hline \multicolumn{3}{|l|}{ HER2 } \\
\hline Positive & $55(53.9 \%)$ & $86(21.9 \%)$ \\
\hline Negative & $45(44.1 \%)$ & $293(74.6 \%)$ \\
\hline Missing & $2(2.0 \%)$ & $14(3.6 \%)$ \\
\hline \multicolumn{3}{|l|}{ Ki67 } \\
\hline High $(>20 \%)$ & $89(87.3 \%)$ & $292(74.3 \%)$ \\
\hline Low $(\leq 20 \%)$ & $3(2.9 \%)$ & $51(13.0 \%)$ \\
\hline Missing & $10(9.8 \%)$ & $50(12.7 \%)$ \\
\hline \multicolumn{3}{|l|}{ St. Gallen } \\
\hline Luminal A like & $0(0 \%)$ & $47(12.0 \%)$ \\
\hline Luminal B like & $9(8.8 \%)$ & $139(35.4 \%)$ \\
\hline HER2 positive & $55(53.9 \%)$ & $86(21.9 \%)$ \\
\hline Triple negative & $35(34.3 \%)$ & $86(21.9 \%)$ \\
\hline Missing & $3(2.9 \%)$ & $35(8.9 \%)$ \\
\hline \multicolumn{3}{|l|}{ Lymph node status } \\
\hline Negative & $23(22.5 \%)$ & $56(14.2 \%)$ \\
\hline Positive & $66(64.7 \%)$ & $268(68.2 \%)$ \\
\hline Missing & $13(12.7 \%)$ & $69(17.6 \%)$ \\
\hline
\end{tabular}

overrepresented in dense breasts. The majority of all tumors were highly proliferative regardless of MD, probably related to the indication of NACT [21]. Scientific inconsistency exists regarding the association between tumor receptor status and MD [22]; however, larger tumor size and positive lymph node status are suggested to be linked to high MD [23]. MD changes throughout a woman's life and is strongly associated with hormonal events; however, according to a review by Martin et al. most studies found no association between serum estrogen levels and MD in either pre- or postmenopausal women [24]. MD decreases with increasing age, with a steep decline during the perimenopausal period [24]—hence, our stratification according to menopausal status.

There might be several explanations as to why women with low MD could be more likely to accomplish pCR than their counterparts with denser breasts. Although much has been written about the biological links between $\mathrm{MD}$ and risk of $\mathrm{BC}$, to our knowledge, no prevailing biological explanation has been presented regarding MD and response to NACT. Response to treatment is influenced not only by tumor characteristics but also by host factors, e.g., age and BMI; we believe that MD can be considered to be one of these host factors, representing the microenvironment of the surrounding breast tissue [14]. On a tissue level, the relationship of mitogens (e.g., insulin growth factor and prolactin) and mutagens (e.g., urinary malondialdehyde, an indicator of oxidative stress) makes MD a proliferative and pro-inflammatory environment [24, 25]. We believe that the same mechanism responsible for tumor initiation and tumor growth may be responsible for a poorer response to treatment in dense breasts. Also, the higher pressure gradient and the higher number of molecules to interact with in a dense breast in comparison to a less dense breast can hypothetically obstruct the delivery of the systemically administrated drug to the tumor site [26-28]. In a study of triple negative BC receiving adjuvant chemotherapy, high MD was associated with higher rates of locoregional recurrence [29]. In a review, Shawky et al. found an adverse impact of high MD on local relapse; however, the emphasis was on radiotherapy, with only a minority of the patients receiving chemotherapy [30]. It is tempting to speculate on whether our results from a mixed BC subtype cohort are also applicable in the adjuvant setting, i.e., if women with dense breasts might experience an inferior locoregional effect of the adjuvant chemotherapy treatment, resulting in higher rates of locoregional recurrence.

Only a few patients had tumors classified as luminal A-like $(N=47)$, of which none accomplished pCR. A total of 148 patients were assigned to the luminal B-like group; due to the underlying indication for NACT, we consider these and similar numbers to be expected. At present, 


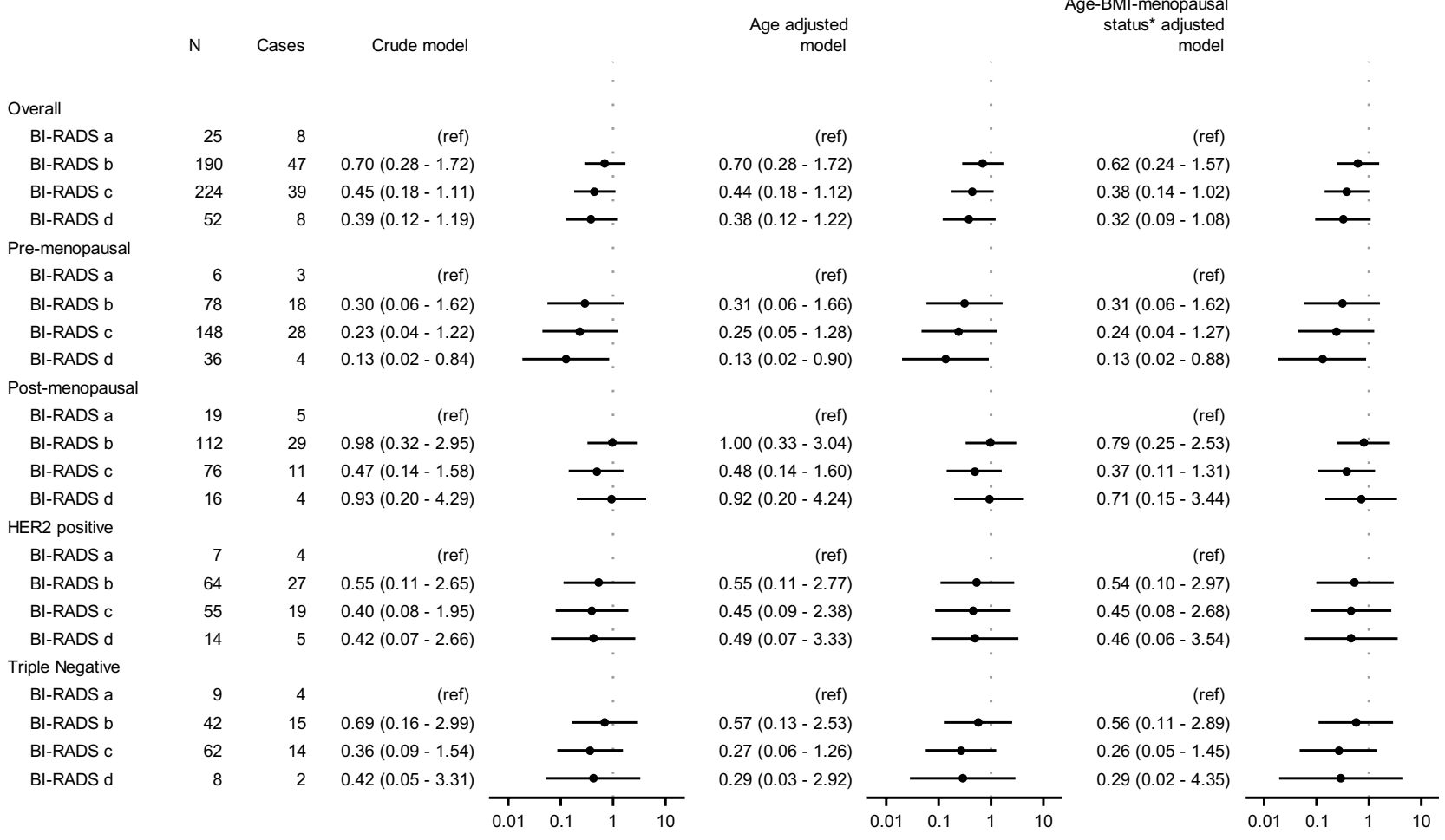

Fig. 2 Forest plot: associations between mammographic density at baseline and pathological complete response following neoadjuvant chemotherapy (BI-RADS a vs. b, c and d, respectively). The fol-

according to national guidelines, it is recommended that NACT be offered to patients with large tumors (T3/T4), patients with positive lymph node status in the axilla, and patients with tumors larger than $20 \mathrm{~mm}$ and, simultaneously, other risk factors, e.g., triple negative tumor or HER2 positivity $[9,10]$. Due to no or only a few $(n=9)$ events of pCR in patients with luminal A-like or luminal B-like, respectively, it was not possible to conduct the logistic regression within the luminal-like subtypes. It is widely known that tumors of luminal-like subtypes have a lower rate of $\mathrm{pCR}$ following NACT in comparison to HER2 positive and triple negative subtypes [12]. Our results indicate a response rate of $<2 \%$ and $6 \%$ for luminal A-like and luminal B-like, respectively-and, thus, relatively low rates of pCR.

Some study limitations must be discussed. The patients received their oncological treatment between 2005 and 2019, and the recommended treatment changed during this wide timespan. The most apparent differences were more stringency with regard to the recommended treatment of chemotherapy (three cycles of FEC/EC combined with three cycles of taxanes) and the fact that double HER2-blockade was given to the patients treated in the more recent years. One shortcoming of this study is that information about the indication for NACT is lacking; thus, one can only hypothesize lowing footnote should be written below the image: *Applicable to: "Overall", "HER2 positive", and "Triple negative"

regarding a potential shift in indication in the two different cohorts. One would assume that a larger proportion of patients received NACT in a down-staging purpose in the early years, although this is not reflected in the only marginally larger tumors seen in the retrospective cohort. A larger proportion of patients in the prospective cohort had axillary lymph node metastases, most likely due to a shift in indication for NACT. The rates of pCR (of patients included in the logistic regression models) in the two cohorts were rather similar and consistent with the previous literature [12]. We classified the patients as postmenopausal when age $\geq 55$ years; hence, some patients might have been misclassified in terms of menopausal status. However, this does not influence the result in the unstratified, unadjusted logistic regression model. We did not have access to raw data mammograms for cohort 1 , ruling out MD assessment by many automatic volumetric software programs. However, our choice of method, BI-RADS, is a widely clinically used method and our results are, thus, easier to applicate in a clinical setting. Given the somewhat inconsistent results of our previous studies [15, 16], our present study shows point estimates slightly closer to 1 and narrower CI, resulting in a more precise conclusion

In conclusion, it seemed as though patients with higher MD at baseline were less likely to reach pCR after NACT 
compared to patients with less dense breasts. This finding was more pronounced in premenopausal women. Larger studies are needed to perform subgroup analyses based on surrogate subtype to make MD useful as a predictive biomarker in the neoadjuvant clinical setting.

Acknowledgments We thank all the participants in the study. The authors thank research nurse Lina Zander for excellent study coordination. We thank all personnel at Unilabs Malmö and Helsingborg for their excellent care of the study patients. We also thank Aki Tuuliainen at Karolinska Institute for technical help, which enabled saving of raw data.

Authors contribution IS participated in designing the study, created study protocols, coordinated the enrollment of patients, collected data, wrote the statistical plan, interpreted data, solely drafted the manuscript (except for "Statistical analyses"), and coordinated revisions to the manuscript. DF provided technical support during image collection, interpreted data, and revised the manuscript. UH assisted in creating the statistical plan, performed statistical analyses, interpreted data, cowrote the "Statistical analyses" section of the manuscript, and substantially revised the manuscript. HS made the BI-RADS classification for cohort 1 , contributed to the interpretation of the results, and revised the manuscript. PH participated in the design of the study, provided technical support during image collection for cohort 2, interpreted data, and revised the manuscript. SZ participated in the general design of the study, interpreted data, and contributed to the revision of the manuscript. SB was the main contributor to the initial design of the study, interpreted data, and revised the manuscript. All authors have read and approved the final manuscript.

Funding Open Access funding provided by Lund University. This work was supported by grants from the Swedish Breast Cancer Group (BRO) and the Governmental Funding of Clinical Research within the National Health Services. Funding resources had no role in the study design, data collection, analyses, data interpretation, writing of the manuscript, or the decision to submit the manuscript for publication.

Data availability The datasets used and/or analyzed in the current study are available from the corresponding author on reasonable request.

\section{Compliance with ethical standards}

Conflict of interest SZ and HS have received speakers' fees and travel support from Siemens Healthcare AG. SZ has received consultancy fees from Collective Minds Radiology AB. PH is a member of a scientific advisory board for: Cancer Research UK, iCAD and Atossa Genetics. SB has received speakers' fees from Pfizer, is a member of a Pfizer advisory board, and has received travel support from Roche. The other authors declare they have no competing interests.

Ethical approval All procedures performed in studies involving human participants were in accordance with the ethical standards of the institutional and/or national research committee, and with the 1964 Helsinki declaration and its later amendments or comparable ethical standards. The study was approved by the Regional Ethics Committee in Lund, Sweden (Committee's Reference Number: 2014/13, 2014/521 and 2016/521).

Informed consent Cohort 1: In accordance with the decision from the ethics committee, all living patients received a written letter asking for their consent at the time of the study. Patients declining participation were asked to provide notice to the researchers either by phone or email. Cohort 2: Informed written consent was obtained from all individual participants included in the study.

Open Access This article is licensed under a Creative Commons Attribution 4.0 International License, which permits use, sharing, adaptation, distribution and reproduction in any medium or format, as long as you give appropriate credit to the original author(s) and the source, provide a link to the Creative Commons licence, and indicate if changes were made. The images or other third party material in this article are included in the article's Creative Commons licence, unless indicated otherwise in a credit line to the material. If material is not included in the article's Creative Commons licence and your intended use is not permitted by statutory regulation or exceeds the permitted use, you will need to obtain permission directly from the copyright holder. To view a copy of this licence, visit http://creativecommons.org/licenses/by/4.0/.

\section{References}

1. Bray F, Ferlay J, Soerjomataram I, Siegel RL, Torre LA, Jemal A (2018) Global cancer statistics 2018: GLOBOCAN estimates of incidence and mortality worldwide for 36 cancers in 185 countries. CA Cancer J Clin 68(6):394-424. https://doi.org/10.3322/ caac. 21492

2. Sherratt MJ, McConnell JC, Streuli CH (2016) Raised mammographic density: causative mechanisms and biological consequences. Breast Cancer Res 18(1):45. https://doi.org/10.1186/ s13058-016-0701-9

3. Huo CW, Chew GL, Britt KL, Ingman WV, Henderson MA, Hopper JL, Thompson EW (2014) Mammographic density-a review on the current understanding of its association with breast cancer. Breast Cancer Res Treat 144(3):479-502. https://doi.org/10.1007/ s10549-014-2901-2

4. Engmann NJ, Golmakani MK, Miglioretti DL, Sprague BL, Kerlikowske K, Breast Cancer Surveillance C (2017) Populationattributable risk proportion of clinical risk factors for breast cancer. JAMA Oncol 3(9):1228-1236. https://doi.org/10.1001/jamao ncol.2016.6326

5. Goldhirsch A, Winer EP, Coates AS, Gelebr RD, Piccart-Gebhart M, Thurlimann B, Senn HJ, Panel M (2013) Personalizing the treatment of women with early breast cancer: highlights of the St Gallen international expert consensus on the primary therapy of early breast cancer 2013. Ann Oncol 24(9):2206-2223. https:// doi.org/10.1093/annonc/mdt303

6. Perou CM, Sorlie T, Eisen MB, van de Rijn M, Jeffrey SS, Rees CA, Pollack JR, Ross DT, Johnsen H, Akslen LA, Fluge O, Pergamenschikov A, Williams C, Zhu SX, Lonning PE, BorresenDale AL, Brown PO, Botstein D (2000) Molecular portraits of human breast tumours. Nature 406(6797):747-752. https://doi. org/10.1038/35021093

7. Cheang MC, Chia SK, Voduc D, Gao D, Leung S, Snider J, Watson M, Davies S, Bernard PS, Parker JS, Perou CM, Ellis MJ, Nielsen TO (2009) Ki67 index, HER2 status, and prognosis of patients with luminal B breast cancer. J Natl Cancer Inst 101(10):736-750. https://doi.org/10.1093/jnci/djp082

8. Goldhirsch A, Wood WC, Coates AS, Gelebr RD, Thurlimann B, Senn HJ, Panel M (2011) Strategies for subtypes-dealing with the diversity of breast cancer: highlights of the St. Gallen International Expert Consensus on the Primary Therapy of Early Breast Cancer 2011. Ann Oncol 22(8):1736-1747. https://doi. org/10.1093/annonc/mdr304

9. Burstein HJ, Curigliano G, Loibl S, Dubsky P, Gnant M, Poortmans P, Colleoni M, Denkert C, Piccart-Gebhart M, Regan M, Senn HJ, Winer EP, Thurlimann B, Members of the St. Gallen 
International Consensus Panel on the Primary Therapy of Early Breast C (2019) Estimating the benefits of therapy for early-stage breast cancer: the St Gallen International Consensus Guidelines for the primary therapy of early breast cancer 2019. Ann Oncol 30(10):1541-1557. https://doi.org/10.1093/annonc/mdz235

10. Regionalt Cancercentrum Nationellt vårdprogram 2020 - Bröstcancer https://kunskapsbanken.cancercentrum.se/globalassets/ cancerdiagnoser/brost/vardprogram/nationellt-vardprogram-brost cancer.pdf. Accessed 29 Sep 2020.

11. Early Breast Cancer Trialists' Collaborative G (2018) Longterm outcomes for neoadjuvant versus adjuvant chemotherapy in early breast cancer: meta-analysis of individual patient data from ten randomised trials. Lancet Oncol 19(1):27-39. https:// doi.org/10.1016/S1470-2045(17)30777-5

12. Houssami N, Macaskill P, von Minckwitz G, Marinovich ML, Mamounas E (2012) Meta-analysis of the association of breast cancer subtype and pathologic complete response to neoadjuvant chemotherapy. Eur J Cancer 48(18):3342-3354. https://doi. org/10.1016/j.ejca.2012.05.023

13. Elsamany S, Alzahrani A, Abozeed WN, Rasmy A, Farooq MU, Elbiomy MA, Rawah E, Alsaleh K, Abdel-Aziz NM (2015) Mammographic breast density: predictive value for pathological response to neoadjuvant chemotherapy in breast cancer patients. Breast 24(5):576-581. https://doi.org/10.1016/j.breas t.2015.05.007

14. Castaneda CA, Flores R, Rojas K, Flores C, Castillo M, Milla E (2014) Association between mammographic features and response to neoadjuvant chemotherapy in locally advanced breast carcinoma. Hematol Oncol Stem Cell Ther 7(4):149-156. https://doi. org/10.1016/j.hemonc.2014.09.001

15. Skarping I, Fornvik D, Sartor H, Heide-Jorgensen U, Zackrisson S, Borgquist S (2019) Mammographic density is a potential predictive marker of pathological response after neoadjuvant chemotherapy in breast cancer. BMC Cancer 19(1):1272. https:// doi.org/10.1186/s12885-019-6485-4

16. Skarping I, Fornvik D, Heide-Jorgensen U, Sartor H, Hall P, Zackrisson S, Borgquist S (2020) Mammographic density changes during neoadjuvant breast cancer treatment: NeoDense, a prospective study in Sweden. Breast 53:33-41. https://doi.org/10.1016/j.breas t.2020.05.013

17. Sickles E DOC, Bassett LW, et al (2013) ACR BI-RADS® Mammography. In: ACR BI-RADS ${ }^{\circ}$ Atlas, Breast Imaging Reporting and Data System. American College of Radiology, Reston, VA

18. Amin MB, Greene FL, Edge SB, Compton CC, Gershenwald JE, Brookland RK, Meyer L, Gress DM, Byrd DR, Winchester DP (2017) The Eighth Edition AJCC Cancer Staging Manual: Continuing to build a bridge from a population-based to a more "personalized" approach to cancer staging. CA Cancer J Clin 67 (2):93-99. https://doi.org/https://doi.org/10.3322/caac.21388

19. Habel LA, Dignam JJ, Land SR, Salane M, Capra AM, Julian TB (2004) Mammographic density and breast cancer after ductal carcinoma in situ. J Natl Cancer Inst 96(19):1467-1472. https:// doi.org/10.1093/jnci/djh260

20. Greenland S, Senn SJ, Rothman KJ, Carlin JB, Poole C, Goodman SN, Altman DG (2016) Statistical tests, P values, confidence intervals, and power: a guide to misinterpretations. Eur J Epidemiol 31(4):337-350. https://doi.org/10.1007/s10654-016-0149-3

21. Hashmi AA, Hashmi KA, Irfan M, Khan SM, Edhi MM, Ali JP, Hashmi SK, Asif H, Faridi N, Khan A (2019) Ki67 index in intrinsic breast cancer subtypes and its association with prognostic parameters. BMC Res Notes 12(1):605. https://doi.org/10.1186/ s13104-019-4653-x

22. Boyd NF, Martin LJ, Yaffe MJ, Minkin S (2011) Mammographic density and breast cancer risk: current understanding and future prospects. Breast Cancer Res 13(6):223. https://doi.org/10.1186/ bcr2942

23. Bertrand KA, Tamimi RM, Scott CG, Jensen MR, Pankratz V, Visscher D, Norman A, Couch F, Shepherd J, Fan B, Chen YY, Ma L, Beck AH, Cummings SR, Kerlikowske K, Vachon CM (2013) Mammographic density and risk of breast cancer by age and tumor characteristics. Breast Cancer Res 15(6):R104. https:// doi.org/10.1186/bcr3570

24. Martin LJ, Boyd NF (2008) Mammographic density. Potential mechanisms of breast cancer risk associated with mammographic density: hypotheses based on epidemiological evidence. Breast Cancer Res 10(1):201. https://doi.org/10.1186/bcr1831

25. Huo CW, Chew G, Hill P, Huang D, Ingman W, Hodson L, Brown KA, Magenau A, Allam AH, McGhee E, Timpson P, Henderson MA, Thompson EW, Britt K (2015) High mammographic density is associated with an increase in stromal collagen and immune cells within the mammary epithelium. Breast Cancer Res 17:79. https://doi.org/10.1186/s13058-015-0592-1

26. Cox TR, Erler JT (2011) Remodeling and homeostasis of the extracellular matrix: implications for fibrotic diseases and cancer. Dis Model Mech 4(2):165-178. https://doi.org/10.1242/ dmm.004077

27. Swartz MA, Fleury ME (2007) Interstitial flow and its effects in soft tissues. Annu Rev Biomed Eng 9:229-256. https://doi. org/10.1146/annurev.bioeng.9.060906.151850

28. Minchinton AI, Tannock IF (2006) Drug penetration in solid tumours. Nat Rev Cancer 6(8):583-592. https://doi.org/10.1038/ $\operatorname{nrc} 1893$

29. Bae MS, Moon HG, Han W, Noh DY, Ryu HS, Park IA, Chang JM, Cho N, Moon WK (2016) Early Stage Triple-Negative Breast Cancer: Imaging and Clinical-Pathologic Factors Associated with Recurrence. Radiology 278(2):356-364. https://doi.org/10.1148/ radiol.2015150089

30. Shawky MS, Huo CW, Henderson MA, Redfern A, Britt K, Thompson EW (2019) A review of the influence of mammographic density on breast cancer clinical and pathological phenotype. Breast Cancer Res Treat 177(2):251-276. https://doi. org/10.1007/s10549-019-05300-1

Publisher's Note Springer Nature remains neutral with regard to jurisdictional claims in published maps and institutional affiliations.

Ida Skarping MD, PhD, Physician at Skane University Hospital, Lund University, Skane University Hospital, Sweden.

Daniel Förnvik Medical Physicist, PhD, Medical Radiation Physics, Department of Translational Medicine, Lund University, Skane University Hospital, Sweden.

Uffe Heide-Jørgensen MSc, PhD, Statistician in the Department of Clinical Epidemiology, Aarhus University Hospital, Aarhus, Denmark.

Hanna Sartor MD, PhD, Specialist in Radiology, Associate professor, Department of Imaging and Functional Medicine, Skane University Hospital, and Diagnostic Radiology, Department of Translational Medicine, Lund University, Sweden.

Per Hall MD, PhD, Professor at the Department of Medical Epidemiology and Biostatistics, Karolinska Institutet, Sweden. 
Sophia Zackrisson MD, PhD, Professor, Senior Consultant, Department of Imaging and Functional Medicine, Skane University Hospital, and Diagnostic Radiology, Department of Translational Medicine, Lund University, Sweden.
Signe Borgquist MD, PhD, Professor, Senior Consultant, Department of Oncology, Aarhus University Hospital, Aarhus, Denmark. Visiting Professor, Division of Oncology and Pathology, Lund University, Sweden. 